\title{
Portosystemic Shunt Prevents Apoptosis in Rat Intestinal Mucosa Caused by Total Hepatic Ischemia
}

\author{
A. Bedirlia O.Sakrak ${ }^{a} \quad$ I. Soyuer ${ }^{b} \quad$ S. Muhtaroglu ${ }^{c}$ \\ aDepartments of General Surgery, University of Gazi, School of Medicine, Ankara, and Departments of \\ bPathology and ${ }^{\mathrm{c} B i o c h e m i s t r y, ~ U n i v e r s i t y ~ o f ~ E r c i y e s, ~ S c h o o l ~ o f ~ M e d i c i n e, ~ K a y s e r i, ~ T u r k e y ~}$
}

\section{Key Words}

Total hepatic ischemia $\cdot$ Portosystemic shunt $\cdot$ Intestinal epithelium · Apoptosis

\begin{abstract}
Background: Prolonged splanchnic congestion due to total hepatic ischemia (THI) has been shown to induce damage to the intestinal mucosa. The present study was conducted to examine whether the protective effect of portosystemic shunt (PSS) can be seen on apoptosis of intestinal mucosa in a rat model of THI. Methods: Adult male Wistar rats were divided into the following 3 groups: control group; the THI group underwent THI for $30 \mathrm{~min}$, and the PSS group was subjected to THI for 30 min with PSS. Rats were killed after 1, 2, and $6 \mathrm{~h}$ of reperfusion. For each time point, levels of serum liver enzymes, intestinal morphology, malondialdehyde (MDA) contents and DNA fragmentation in intestinal tissue were determined. In addition, the 7-day survival rate was measured. Results: The 7-day survival rate of THI group remained at $50 \%$, whereas that of PSS group was significantly higher at $90 \%(p<0.01)$. Serum AST and ALT levels of the THI and PSS groups rapidly increased after reperfusion, reaching peak values at $2 \mathrm{~h}$. MDA levels after 1 and $2 \mathrm{~h}$ of reperfusion in the THI group were significantly increased as compared with the control group
\end{abstract}

( $p<0.001$ ). Increases in the percentage of fragmented DNA peaked $1 \mathrm{~h}$ after reperfusion in the THI group. PSS resulted in the reduction of DNA fragmentation and preserved the macroscopic and microscopic appearance of the intestinal mucosa. Conclusions: Splanchnic congestion due to portal occlusion increased apoptosis in the rat intestinal mucosa. PSS is very effective in counteracting the principal negative effects of total hepatic ischemia.

Copyright $\odot 2004$ S. Karger AG, Basel

\section{Introduction}

The Pringle maneuver is performed to minimize hepatic bleeding by temporary portal triad clamping during various surgical procedures, such as repair of liver trauma, major hepatectomy for tumor resection, and liver transplantation. This maneuver reduces blood loss and operating time, but damage to the liver and other organs has been noted [1-3]. Prolonged clamping of the portal vein has been shown to induce different negative pathophysiological events, such as release of endotoxin, tumor necrosis factor (TNF), damage to the intestinal mucosa, and bacterial translocation [1,3-5]. Many of these adverse effects are related to damage to the gut owing to prolonged splanchnic venous stasis. Furthermore, splanchnic congestion may have a greater influence than hepatic isch-

\section{KARGER}

Fax +41613061234

E-Mail karger@karger.ch

www. karger.com
(C) 2004 S. Karger AG, Basel

0014-312X/04/0365-0293\$21.00/0

Accessible online at:

www. karger.com/esr
Abdulkadir Bedirli, MD

Mesa Koru Sit. Fulya Blok, 85/39

TR-06810 Cayyolu, Ankara (Turkey)

Tel. +90 312 2025724, Fax +90 312 2124647, E-Mail bedirlia@gazi.edu.tr 
emia has in contributing to the deterioration of the physiological state. The results indicate that, in rats, there is a high probability of an irreversible state of shock after 30min hepatic inflow occlusion when veno-venous bypass is not applied [6]. Portocaval shunt allows decompression of the splanchnic circulation and prevents mucosal and submucosal injury during total hepatic ischemia (THI). The mechanisms by which the intestine is damaged during THI are not well defined. Two distinct modes of cell death, apoptosis and necrosis, are involved in the destruction of rat small intestinal epithelial cells following an ischemic insult [7, 8]. Experimental models demonstrated that rats undergoing more than $30 \mathrm{~min}$ of portal vein occlusion showed necrosis in intestinal epithelial cells [1, 3]. However, no data are available on the role of apoptotic damage in the rat small intestine during THI. The present study was undertaken to elucidate this question as well as to assess whether this apoptotic pathway could be attenuated by portocaval shunt.

\section{Materials and Methods}

Animal Preparation. Male Wistar rats weighing 200-250 g were used in all experiments. The experimental protocols followed the institution's and the National Research Council's criteria for the care and use of laboratory animals in research. The animals were housed at room temperature in cages under 12-hour light/dark cycles and given free access to water. All surgical procedures were performed under sterile conditions after anesthesia was induced by intraperitoneal pentobarbital sodium $(50 \mathrm{mg} / \mathrm{kg})$. Sodium heparin $(200 \mathrm{IU} / \mathrm{kg})$ was injected via the caudal vein. The animals were divided into the following 3 groups: The control group $(n=24)$ underwent laparotomy and liver manipulation without clamping of the vessels; the THI group $(\mathrm{n}=24)$ underwent cross-clamping of the portal triad for 30 min with microclips (Harvard Apparatus Inc., Natick, Mass., USA), and the portosystemic shunt (PSS) group $(\mathrm{n}=24)$ was subjected to cross-clamping of the portal triad for $30 \mathrm{~min}$ with a PSS. The shunt was placed between a cecal branch of the portal vein and the jugular vein, as described previously [9]. A polyethylene tube, $0.86 \mathrm{~mm}$ inner diameter, was used to prevent splanchnic congestion and portal pooling at the time of clamping of the portal triad. During the course of ischemia, the abdomen was kept moist by repeated irrigation with $0.15 \mathrm{M} \mathrm{NaCl}$ (prewarmed to $37^{\circ} \mathrm{C}$ ). Reperfusion of blood through the ischemic liver was achieved by releasing the microclips and discontinuing the shunt. After release of the clip and return of normal bowel color ( $\sim 10-15 \mathrm{~s}$ later $)$, the abdominal incision was closed in one layer with 4-0 silk sutures. After closing the abdominal wall, all animals were allowed free access to food and water. Eight animals of each group were sacrificed after sampling blood by direct puncture of the abdominal aorta at 1,2, and $6 \mathrm{~h}$ after reperfusion. After sacrifice, the small intestine $10 \mathrm{~cm}$ distal to the gastroduodenal junction was harvested for histologic evaluation, apoptosis, and quantification of lipid peroxidation.

\section{Survival Rate}

Ten animals in each group were used for analysis of survival. The survival rate was calculated from the number of animals living longer than 7 days after operation.

\section{Measurement of Serum AST and ALT Levels}

Serum aspartate aminotransferase (AST) and alanine aminotransferase (ALT) activities were measured to assess the damage to the hepatic parenchyma after 1,2 , and $6 \mathrm{~h}$ of reperfusion using a Technicon RA-XT autoanalyzer (Texa-Lab Inc., Houston, Tex., USA).

\section{Histology}

For histological analysis of the mucosal damage, a section of the mid jejunum, approximately $1.5 \mathrm{~cm}$ long, was immediately fixed in $10 \%$ buffered formalin, subsequently embedded in paraffin, cut into slices of 5-7 $\mu \mathrm{m}$ thickness and stained with hematoxylin and eosin (HE). Histologic assessment was carried out in blinded fashion by 1 pathologist. The grading scheme has been adapted from Chiu et al. [10]. Thus, injury was classified using a semiquantitative grading system where a numerical score was assigned based on the type of mucosal and submucosal damage (table 1). The presence of apoptotic cells was defined by checking cell morphology in HE-stained sections. The characteristic morphological features used to identify apoptotic death included the presence of pyknotic nuclei, condensed chromatin, and nuclear fragmentation [11].

\section{Malondialdehyde Assay}

The intestinal segment was rinsed thoroughly with normal saline $(0.9 \% \mathrm{NaCl})$ and opened longitudinally to expose the intestinal epithelium. The mucosal layer was harvested by gently scraping the epithelium using a glass slide. Mucosal scrapings were placed in $2 \mathrm{ml}$ of $0.1 M$ Tris buffer ( $\mathrm{pH} 7.4$ ) containing $1 \mathrm{~m} M$ EDTA, $50 \mu M$ pyridoxal 5-phosphate, and $5 \mathrm{mM}$ dithiothreitol. The tissues were homogenized twice with a Virsonic 100 (Virtis Company Inc., Gardiner, N.Y., USA) for $15 \mathrm{~s}$ and centrifuged at $30,000 \mathrm{rpm}$ for $30 \mathrm{~min}$. Protein content was determined, and malondialdehyde (MDA) levels in the tissue homogenates were analyzed with a commercially available kit (Lipid Peroxidation Assay Kit II; Calbiochem, La Jolla, Calif., USA). MDA levels are expressed as nanomoles per gram of protein.

\section{DNA Fragmentation Assay}

The mount of fragmented DNA was determined by a modification of the method reported by Cohen and Duke [12]. The whole epithelium of the jejunum without the muscle layer was collected by mechanical scraping with a blade. Mucosal scrapings were vigorously pipetted in $500 \mathrm{ml}$ of PBS, and harvested by centrifugation at $3,000 \mathrm{rpm}$ for $5 \mathrm{~min}$. Pellets were lysed with $0.4 \mathrm{ml}$ of lysing buffer (10 m $M$ Tris, $10 \mathrm{~m} M$ EDTA, $\mathrm{pH} 8.0$ ) containing $0.5 \%$ Triton X-100, and the lysates were centrifuged at $15,000 \mathrm{rpm}$ for $20 \mathrm{~min}$ to separate intact DNA from fragmented chromatin. The supernatant containing fragmented DNA was placed in a separate microfuge tube and both fractions were precipitated for $30 \mathrm{~min}$ at $4{ }^{\circ} \mathrm{C}$ in $0.4 \mathrm{ml}$ of $1 \mathrm{~N}$ perchloric acid. Precipitates were sedimented at $15,000 \mathrm{rpm}$ for $20 \mathrm{~min}$ and the included DNA was hydrolyzed by heating to $90^{\circ} \mathrm{C}$ for $10 \mathrm{~min}$ in $150 \mu \mathrm{l} 1 \mathrm{~N}$ perchloric acid. DNA was quantified by using diphenylamine reaction as previously described [13]. The results are expressed as the percentage of fragmented DNA. 
Table 1. Description of histological grading scheme

\begin{tabular}{ll}
\hline Grade & Histologic changes \\
\hline 0 & $\begin{array}{l}\text { Normal mucosal villi } \\
\text { Development of a subepithelial space, usually at the tip of } \\
\text { the villus, with capillary congestion }\end{array}$ \\
2 & $\begin{array}{l}\text { Extension of the subepithelial space with moderate lifting } \\
\text { of the epithelial layer }\end{array}$ \\
3 & $\begin{array}{l}\text { Massive epithelial lifting down the sides of villi } \\
\text { Denuded villi with lamina propria and dilated capillaries } \\
\text { exposed. Increased cellularity of the lamina propria }\end{array}$ \\
5 & $\begin{array}{l}\text { Digestion and disintegration of the lamina propria, } \\
\text { hemorrhage and ulceration }\end{array}$ \\
\hline
\end{tabular}

From Chiu et al. [10].

Table 2. Survival rates of animals subjected to $30 \mathrm{~min}$ of total hepatic ischemia

\begin{tabular}{llccc}
\hline Groups & Animals & \multicolumn{3}{c}{ Postoperative survival } \\
\cline { 3 - 5 } & & $24 \mathrm{~h}$ & $72 \mathrm{~h}$ & 7 days \\
\hline Control & 10 & $10(100 \%)$ & $10(100 \%)$ & $10(100 \%)$ \\
THI & 10 & $9(90 \%)$ & $6(60 \%)$ & $5(50 \%)$ \\
PSS & 10 & $10(100 \%)$ & $10(100 \%)$ & $9(90 \%)$ \\
\hline
\end{tabular}

\section{Statistical Analysis}

Histology scores are reported as means \pm SEM. All other values are reported as mean \pm SD. Data were compared by analysis of variance with post hoc analysis using the Newman-Keuls test. When a difference was found, specific differences were identified using the Kruskal-Wallis test. Statistical analyses were carried out by using SPSS 10.0 software (SPSS, Chicago, Ill., USA). Values of $\mathrm{p}<0.05$ were accepted as significant.

\section{Results}

\section{Survival Rate}

All control animals survived the laparotomy operation. In the THI group, 4 of 10 animals died within $72 \mathrm{~h}$ after THI. The 7-day survival rate of the THI group remained at $50 \%$, whereas that of the PSS group was significantly higher at $90 \%(\mathrm{p}<0.01)$. Animal survival rates are shown in table 2.

\section{Liver Enzyme Levels}

Serum AST and ALT levels of the THI and PSS groups rapidly increased after reperfusion, reaching peak values at $2 \mathrm{~h}$. A similar trend of exacerbation of liver damage, as

Apoptosis in the Intestinal Mucosa Caused by Total Hepatic Ischemia
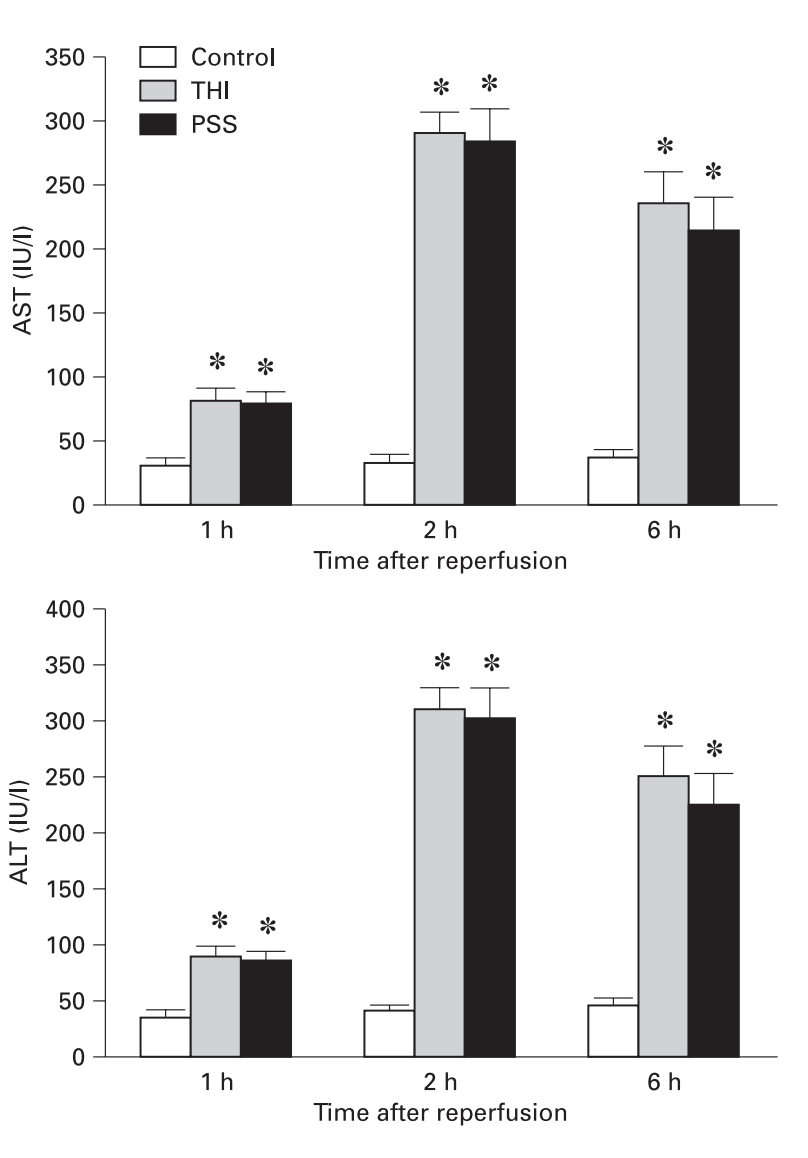

Fig. 1. AST and ALT levels after $30 \mathrm{~min}$ of ischemia and 1, 2, and $6 \mathrm{~h}$ of reperfusion. Values are mean $\pm \mathrm{SD} .{ }^{*} \mathrm{p}<0.01$ vs. control group.

assessed by AST and ALT levels, were observed for the THI and PSS groups. The livers in the shunt group did not benefit from the reduced intestinal tissue injury. The time course of AST and ALT changes in animals are depicted in figure 1.

\section{Malondialdehyde Activity in Intestinal Tissue}

Figure 2 shows the results obtained in the determination of MDA in rats. No significant differences in MDA levels were observed between the control and PSS groups of animals at any reperfusion period. In contrast, MDA levels after 1 and $2 \mathrm{~h}$ of reperfusion in the THI group were significantly increased as compared with control group $(\mathrm{p}<0.01)$.

\section{Apoptosis}

Figure 3 shows the degree of DNA fragmentation in the small intestine in rats. In the THI group, the percent- 


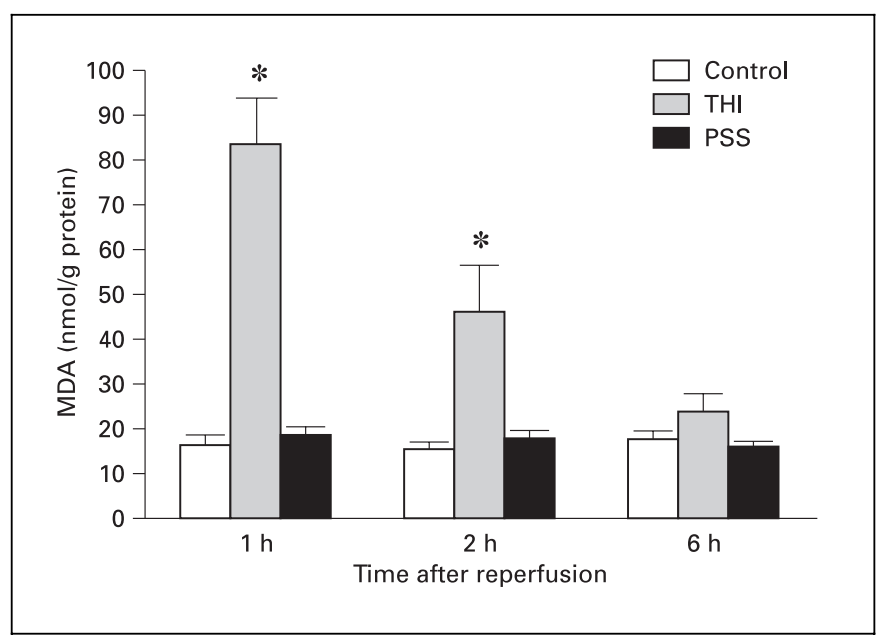

Fig. 2. Effect of total hepatic ischemia and reperfusion on MDA levels in jejunum. Values are means \pm SD. ${ }^{*} \mathrm{p}<0.01$ vs. control group.

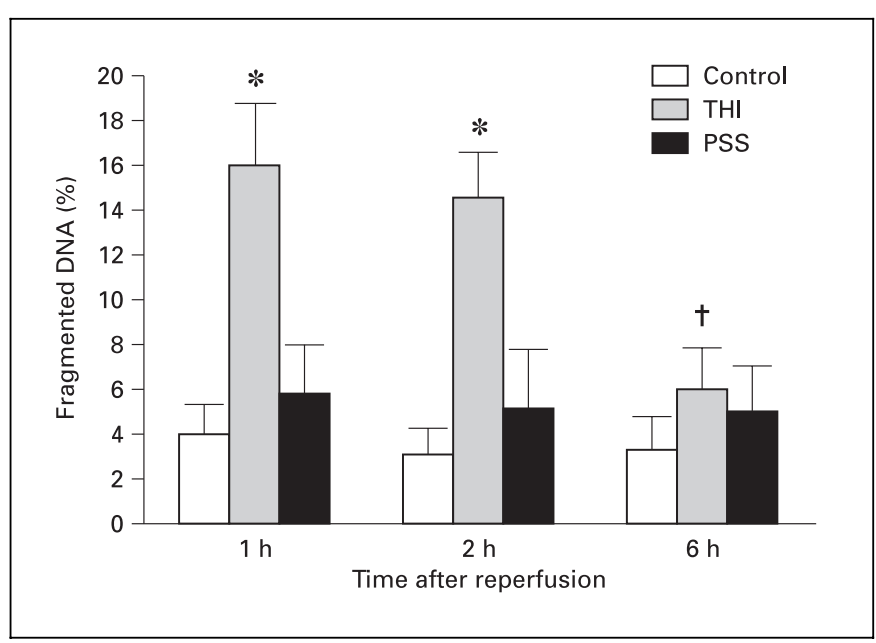

Fig. 3. Percentage of fragmented DNA in the intestinal mucosa after hepatic ischemia-reperfusion. Values are means \pm SD. ${ }^{*} \mathrm{p}<0.01$ vs. control group; ${ }^{\dagger} \mathrm{p}<0.05$ vs. control group.
Table 3. Histopathological evaluation of the intestinal epithelium (mean \pm SEM)

\begin{tabular}{llll}
\hline Group & \multicolumn{3}{l}{ Histologic grade } \\
\cline { 2 - 4 } & $1 \mathrm{~h}$ & $2 \mathrm{~h}$ & $6 \mathrm{~h}$ \\
\hline Control & $0.00 \pm 0.00$ & $0.00 \pm 0.00$ & $0.13 \pm 0.13$ \\
THI & $0.50 \pm 0.27$ & $1.25 \pm 0.37^{*}$ & $2.63 \pm 0.38^{*}$ \\
PSS & $0.25 \pm 0.16$ & $0.38 \pm 0.26$ & $0.25 \pm 0.16$ \\
\hline
\end{tabular}

$* \mathrm{p}<0.01$ vs. control group. age of fragmented DNA significantly increased after reperfusion $(1 \mathrm{~h}, 15.9 \pm 2.9 \% ; 2 \mathrm{~h}, 14.5 \pm 2.1 \% ; 6 \mathrm{~h}, 6.0 \pm$ $1.9 \%)$ compared with the values of the control group $(1 \mathrm{~h}$, $4.0 \pm 1.3 \% ; 2 \mathrm{~h}, 3 \pm 1.3 \% ; 6 \mathrm{~h}, 3.3 \pm 1.5 \%)$. A significant inhibition of DNA fragmentation was observed in the intestinal mucosa collected from rats subjected to THI with PSS. The presence of apoptotic cells was verified by checking cell morphology in HE-stained sections. Our study has shown that apoptosis is suppressed very strongly by the intestine after liver warm ischemia with PSS, compared to liver ischemia alone.

\section{Histologic Examination}

Intestinal mucosa of the sham-operated animals (control group) remained normal as indicated by an injury score of $0.13 \pm 0.13$ and normal villi height at $6 \mathrm{~h}$. There were no significant histologic changes in the small intestine $1 \mathrm{~h}$ after reperfusion in all groups $(\mathrm{p}>0.05)$. As expected, the mucosa of animals subjected to THI for 30 min displayed signs of significant damage with a mean score of $1.25 \pm 0.37$ at $2 \mathrm{~h}$ and $2.63 \pm 0.38$ at $6 \mathrm{~h}$ (fig. 4). In contrast, PSS significantly preserved the macroscopic and microscopic appearance of the intestinal mucosa (mean injury score $0.38 \pm 0.26$ for $2 \mathrm{~h}$ and $0.25 \pm 0.16$ for $6 \mathrm{~h})$.

\section{Discussion}

The Pringle maneuver is performed during hepatectomy because it reduces intraoperative blood loss during dissection of the hepatic parenchyma. In humans and primates, clamping of the portal vein is well tolerated if there is an efficient portosystemic collateral network through which splanchnic blood can return to the heart. However, small animals do not tolerate prolonged caval and/or por- 

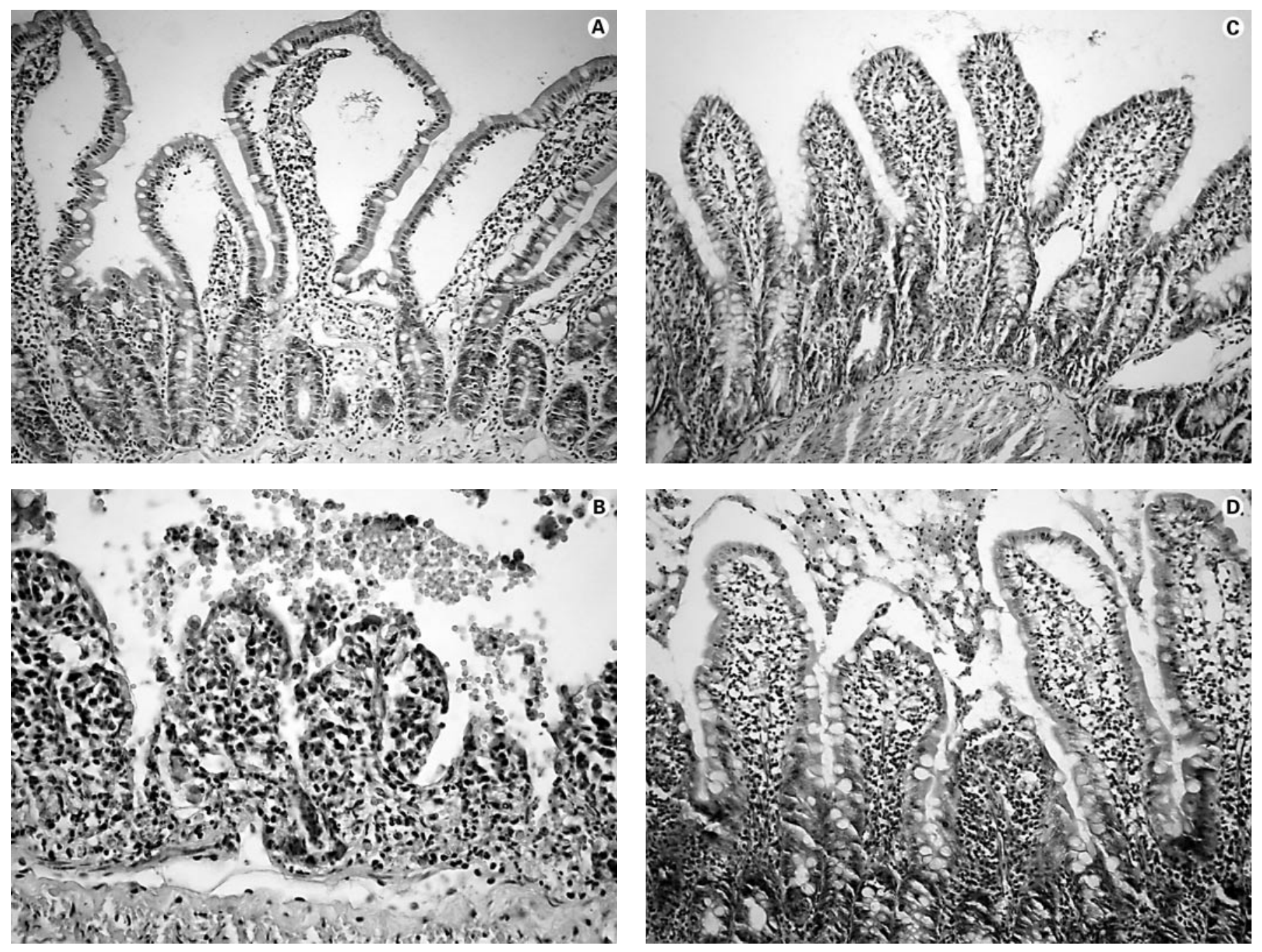

Fig. 4. Micrographs of jejunum mucosa from rats subjected to cross-clamping of the portal triad for $30 \mathrm{~min}$, thereafter declamping and reperfusion for $6 \mathrm{~h}$. Paraffin sections were stained with HE. A, B Small intestinal histology showed marked mucosal damage with massive epithelial lifting and focal areas of villi denudation in the THI group. C, D Intestinal injury was much less severe in animals that underwent PSS.

tal clamping. Previous studies have shown that $50 \%$ of rats with 45-min warm ischemia of the liver died within 7 days and no rat survived after completely blocking the hepatic artery and portal vein for $60 \mathrm{~min}$ [14]. This lead to the impetus for various investigators to seek alternative methods to attenuate splanchnic venous stasis. Portacaval shunt, splenocaval shunt, extracorporeal PSS, and clamping of the celiac and superior mesenteric arteries are methods used for this purpose [3-5, 9]. Suzuki et al. [15] performed intracorporeal anastomosis between the splenic vein and inferior vena cava. Their results showed that 60 min of warm ischemia of the liver in the rat is tolerable when the intestinal blood is shunted into systemic circulation. Sankary et al. [4] reported that rats subjected to $120 \mathrm{~min}$ of normothermic liver ischemia survived for more than 1 day when a splenocaval shunt was applied. In our study, we performed an extracorporeal PSS by placing a polyethylene tube between a cecal branch of the portal vein and a jugular vein. The results show that all rats with 30-min warm ischemia of the liver in the PSS group survived for more than 3 days. The 7-day survival rate of the THI group remained at 50\%, whereas that of the PSS group was significantly higher at $90 \%$. 
The intestinal mucosa is probably one of the most sensitive tissues to ischemia. The mechanisms by which the intestine is damaged after THI are not well defined. Contributing factors include reactive oxygen species (ROS) and the local recruitment of inflammatory leukocytes [16]. ROS and peroxynitrite produce cellular injury and necrosis via several mechanisms including peroxidation of membrane lipids, protein denaturation and DNA damage. Concentrations of tissue MDA in the small intestine proved to be elevated after ischemia-reperfusion injury [17-19]. In this study, significant increases in intestinal MDA levels were detected 1 and $2 \mathrm{~h}$ after reperfusion of the 30-min THI. PSS preventively diminished the increase in tissue MDA concentration. Liu et al. [1] found extensive destruction of the microvilli of epithelial cells and highly enlarged mitochondria in intestinal cells in the animals subjected to 90 or $120 \mathrm{~min}$ of THI. A mechanical obstacle of the hemodynamics of the splanchnic organs during THI is believed to be a main factor in this damage. In this study, there was moderate mucosal damage consistent with ischemic injury, ranging from capillary congestion to massive epithelial lifting in animals that received THI alone. Our data provide evidence that PSS reduces morphological injury due to THI.

In the past, necrosis has been presumed to be the chief cause of epithelial cell death following an ischemic insult. More recent studies indicated, however, that apoptosis is a significant and perhaps the principal contributor to cell death after ischemia-reperfusion injury $[8,18,20]$. In contrast to necrosis, apoptosis is an active process of genedirected cellular self-destruction characterized by morphological changes such as cell shrinkage with intact organelles remaining, condensation of chromatin into crescent caps at the nucleus and cytoplasm to form apoptotic bodies [7]. Previous studies of intestinal ischemia showed that induction of apoptosis occurs during the ischemic phase but continues into the early reperfusion phase $[8,20]$. Noda et al. [7] demonstrated that DNA fragmentation reaches a peak $1 \mathrm{~h}$ after reperfusion and returns to baseline values by $6 \mathrm{~h}$. Farber et al. [21] reported that in their murine model of segmental mesenteric ischemia, they observed apoptosis to a level that was shown in murine superior mesenteric artery occlusion models. Increased ischemia-reperfusion injury correlated with increased intestinal apoptosis, and it was maximal at 70 min of ischemia. It was our goal to study the role of apoptosis in the intestine due to THI and to evaluate the effects of PSS on apoptosis inhibition. Thirty minutes of THI were chosen because this time point yielded sufficient but not an excessive degree of tissue injury. THI resulted in significantly increased apoptosis that was maximal at $1 \mathrm{~h}$ of reperfusion. Although apoptosis is seen in the early stages of reperfusion, serious histopathological changes are obtained in the later stages in our study. The protective effect of the PSS on intestinal injury during ischemiareperfusion of the liver and postoperative survival was described previously [3]. Recently, apoptosis induction has also been demonstrated in the rat intestine after the Pringle maneuver [22]. What is new about the present study is the information that PSS prevented apoptosis of the rat intestine after hepatic ischemia.

As a result, short-term THI and reperfusion induce apoptosis in the intestinal epithelium. The use of PSS during THI can prevent the development of splanchnic congestion with significant ability to attenuate apoptosis and tissue damage in the small intestine.

\section{References}

1 Liu DL, Jeppsson B, Hakansson CH, Odselius $\mathrm{R}$ : Multiple-system organ damage resulting from prolonged hepatic inflow interruption. Arch Surg 1996;131:442-447.

2 Ochiai H, Nakamura S, Suzuki S, Baba S, Baba S: Pancreatic damage resulting from temporary portal triad interruption during partial hepatectomy: Protective effect of a prostaglandin $\mathrm{I}_{2}$ analogue. J Surg Res 1997;73:129-136.

3 Suzuki S, Nakamura S, Sakaguchi T, Mitsuoka H, Tsuchiya Y, Kojima Y, Konno H, Baba S: Pathophysiological appraisal of a rat model of total hepatic ischemia with an extracorporeal portosystemic shunt. J Surg Res 1998;80:2227.
4 Sankary HN, Yin DP, Chong AS, Ma LL, Blinder L, Shen JK, Foster P, Liu LP, Li C, Williams JW: The portosystemic shunt protects liver against ischemic reperfusion injury. Transplantation 1999;68:958-963.

5 Liu L, Jeppsson B, Bengmark S: Bacterial translocation into portal blood from the gut during portal triad occlusion. Dig Surg 1992;9: 95-101.

6 Kogure K, Suzuki M: Effects of hepatic inflow occlusion on changes in plasma potassium, histamine, and norepinephrine in rats. Circ Shock 1992;36:290-298.

7 Noda T, Iwakiri R, Fujimoto K, Shuzo Matsuo S, Aw TY: Programmed cell death induced by ischemia-reperfusion in rat intestinal mucosa. Am J Physiol 1998;274:G270-G276.
8 Shah KA, Shurey S, Green CJ: Apoptosis after intestinal ischemia-reperfusion injury: A morphological study. Transplantation 1997;64: 1393-1397.

9 Suzuki S, Nakamura S, Koizumi T, Sakaguchi S, Baba S, Muro H, Fujise Y: The beneficial effect of prostaglandin $\mathrm{I}_{2}$ analog on ischemic rat liver. Transplantation 1991;52:978-983.

10 Chiu CJ, McArdle AH, Brown R, Scott HJ, Gurd FN: Intestinal mucosal lesion in low-flow states. Arch Surg 1970;101:478-483.

11 Helmrath MA, Erwin CR, Shin CE, Warner BW: Enterocyte apoptosis is increased following small bowel resection. J Gastrointest Surg 1998;2:44-49. 
12 Cohen JJ, Duke RC: Glucocorticoid activation of a calcium-dependent endonuclease in thymocyte nuclei leads to cell death. J Immunol 1984;132:38-42.

13 Burton K: A study of the conditions and mechanism of the diphenylamine reaction for the colorimetric estimation of deoxyribonucleic acid. Biochem J 1956;62:315-323.

14 Sumimoto R, Southard JH, Bezler FO: Liver from fasted rats acquire resistance to warm and cold ischemia injury. Transplantation 1993;55: 728-732.

15 Suzuki S, Nakamura S, Sakaguchi T, Ochiai H Konno H, Baba S, Baba S: Alteration of reticuloendothelial phagocytic function and tumor necrosis factor- $\alpha$ production after total hepatic ischemia. Transplantation 1997;64:821-827.
16 Schoenberg MH, Beger HG: Reperfusion injury after intestinal ischemia. Crit Care Med 1993;21:1376-1386.

17 Parks DA, Shah AK, Granger DN: Oxygen radicals: Effects on intestinal vascular permeability. Am J Physiol 1984;247:G167-G170

18 Bedirli A, Soyuer I, Muhtaroglu S, Guler I: Role of granulocyte-macrophage colony-stimulating factor on apoptosis induced by ischemiareperfusion in the intestinal epithelium. Eur Surg Res 2003;35:657-662.

19 Lai HS, Chen WJ, Chiang LY: Free radical scavenging activity of fullerenol on the ischemia-reperfusion intestine in dogs. World $\mathbf{J}$ Surg 2000;24:450-454.
20 Ikeda H, Suzuki Y, Suzuki M, Koike M, Tamura $\mathrm{J}$, Tong $\mathrm{J}$, Nomura $\mathrm{M}$, Itob G: Apoptosis is a major mode of cell death caused by ischemia and ischemia/reperfusion injury to the rat intestinal epithelium. Gut 1998;42:530-537.

21 Farber A, Connors JP, Friedlander RM, Wagner RJ, Powell RJ, Cronenwett JL: A specific inhibitor of apoptosis decreases tissue injury after intestinal ischemia-reperfusion in mice. $\mathrm{J}$ Vasc Surg 1999;30:752-760.

22 Filos KS, Kirkilesis I, Spiliopoulou I, Scopa CD, Nikolopoulou V, Kouraklis G, Vagianos CE: Bacterial translocation, endotoxaemia and apoptosis following Pringle manoeuvre in rats. Injury 2004;35:35-43. 